\title{
Evaluation of hydrometric network efficacy and user requirements in the Republic of Ireland via expert opinion and statistical analysis
}

\author{
Paul Hynds \\ Technological University Dublin, Paul.Hynds@tudublin.ie \\ Ahmed Nasr \\ Technological University Dublin, ahmed.nasr@tudublin.ie \\ Jean O'Dwyer \\ University College Cork
}

Follow this and additional works at: https://arrow.tudublin.ie/ehsiart

Part of the Medicine and Health Sciences Commons, and the Other Civil and Environmental

Engineering Commons

\section{Recommended Citation}

P.D. Hynds, A.E. Nasr, J. O'Dwyer, Evaluation of hydrometric network efficacy and user requirements in the Republic of Ireland via expert opinion and statistical analysis, Journal of Hydrology, Volume 574, 2019, Pages 851-861, ISSN 0022-1694, DOI: 10.1016/j.jhydrol.2019.04.086.

This Article is brought to you for free and open access by the ESHI Publications at ARROW@TU Dublin. It has been accepted for inclusion in Articles by an authorized administrator of ARROW@TU Dublin. For more information, please contact arrow.admin@tudublin.ie, aisling.coyne@tudublin.ie,gerard.connolly@tudublin.ie. Funder: Environmental Protection Agency (EPA)

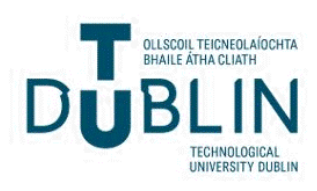


Research papers

\title{
Evaluation of hydrometric network efficacy and user requirements in the Republic of Ireland via expert opinion and statistical analysis
}

\author{
P.D. Hynds ${ }^{\mathrm{a}, *}$, A.E. Nasr ${ }^{\mathrm{b}}$, J. O'Dwyer ${ }^{\mathrm{c}, \mathrm{d}}$ \\ ${ }^{a}$ Environmental Sustainability and Health Institute (ESHI), Technological University Dublin, Ireland \\ ${ }^{\mathrm{b}}$ School of Civil and Structural Engineering, Technological University Dublin, Ireland \\ ${ }^{c}$ School of Biological, Earth and Environmental Sciences, University College Cork, Ireland \\ ${ }^{\mathrm{d}}$ Environmental Research Institute, University College Cork, Ireland
}

\section{A R T I C L E I N F O}

\section{Keywords:}

Hydrometric measurement

Network design

Optimisation

Cross-sectional survey

\begin{abstract}
A B S T R A C T
Decreased funding and shifting governmental priorities have resulted in a contraction of hydrometric measurement in many regions over the past two decades. Moreover, concerns exist with respect to appropriate data usage and (transboundary) exchange, in addition to the compatibility and extent of existing hydrometric datasets. These issues are undoubtedly magnified due to enhanced data demands and increased financial pressures on network managers, thus requiring new approaches to optimising the societal benefits and overall efficacy of hydrometric information for future socio-hydrological resilience.

The current study employed a quantitative cross-sectional expert elicitation of 203 respondents to collate, analyse and assess hydrometric network users' opinions, knowledge and experience. Current usage patterns, perceived network strengths, requirements, and limitations have been identified and discussed within the context of hydrometric resilience in a changing social, economic and natural environment. Findings indicate that small $\left(<30 \mathrm{~km}^{2}\right)$ catchment data are most frequently employed in the Republic of Ireland, particularly with respect to extreme event prediction and flood management. Similarly, small catchments and areas characterised by previous/recent flooding were prioritised for resilience management via network amendment. Over half of those surveyed (50.5\%) reported the current network as inadequate for their professional requirements. Conversely, respondents indicated network efficacy has improved (53.2\%) or remained stable (26.6\%) over the course of their professional career, however, improvements (as defined by individual respondents i.e. network density, data quality, data availability) have not occurred at a sufficient rate. User-defined efficacy (adequacy, resilience) was found to be a somewhat vague, multivariate concept, with no individual predictor identified, however, general data quality, network density, and urban catchment data were the most significant issues among respondents. A significant majority (85.4\%) of respondents indicate that future resilience would be best achieved via network density amendment, with over $60 \%$ favouring geographically and/or categorically focused network increases, as opposed to more general national increases.
\end{abstract}

\section{Introduction}

Effective hydrometric monitoring is vital for provision of data for the assessment, development and management of water resources and the water-related environment (e.g. low flows, flood prevention, bridge design, nutrient management, groundwater resource assessment, etc.) and, as such, their availability and quality underscores research and operational hydrology across the globe (Mishra and Coulibaly, 2009; Cox et al., 2014). Increasing global water demands in concurrence with shifting climate and landuse patterns and a growing worldwide population will necessitate higher levels of sustainable water resource (catchment) management, and an increased ability to accurately predict catchment hydrodynamics (Cheng et al., 2014). Conservative climate modelling (CMIP5) predicts that by 2050, up to 3.4 billion people will be exposed to some level of water resource stress (i.e. scarcity), while an increased exposure to river flooding will affect between 100 million and 580 million people. Accordingly, efficient, accurate and proactive hydrometric monitoring and network design are now required to ensure sustainable water resource management in the face of increasingly frequent hydrological events (Zheng et al., 2018). Additionally, in many regions, a functional hydrometric network is prerequisite to provincial/ federal, national, and/or international regulatory compliance. For

\footnotetext{
* Corresponding author.

E-mail address: hyndsp@tcd.ie (P.D. Hynds).
} 


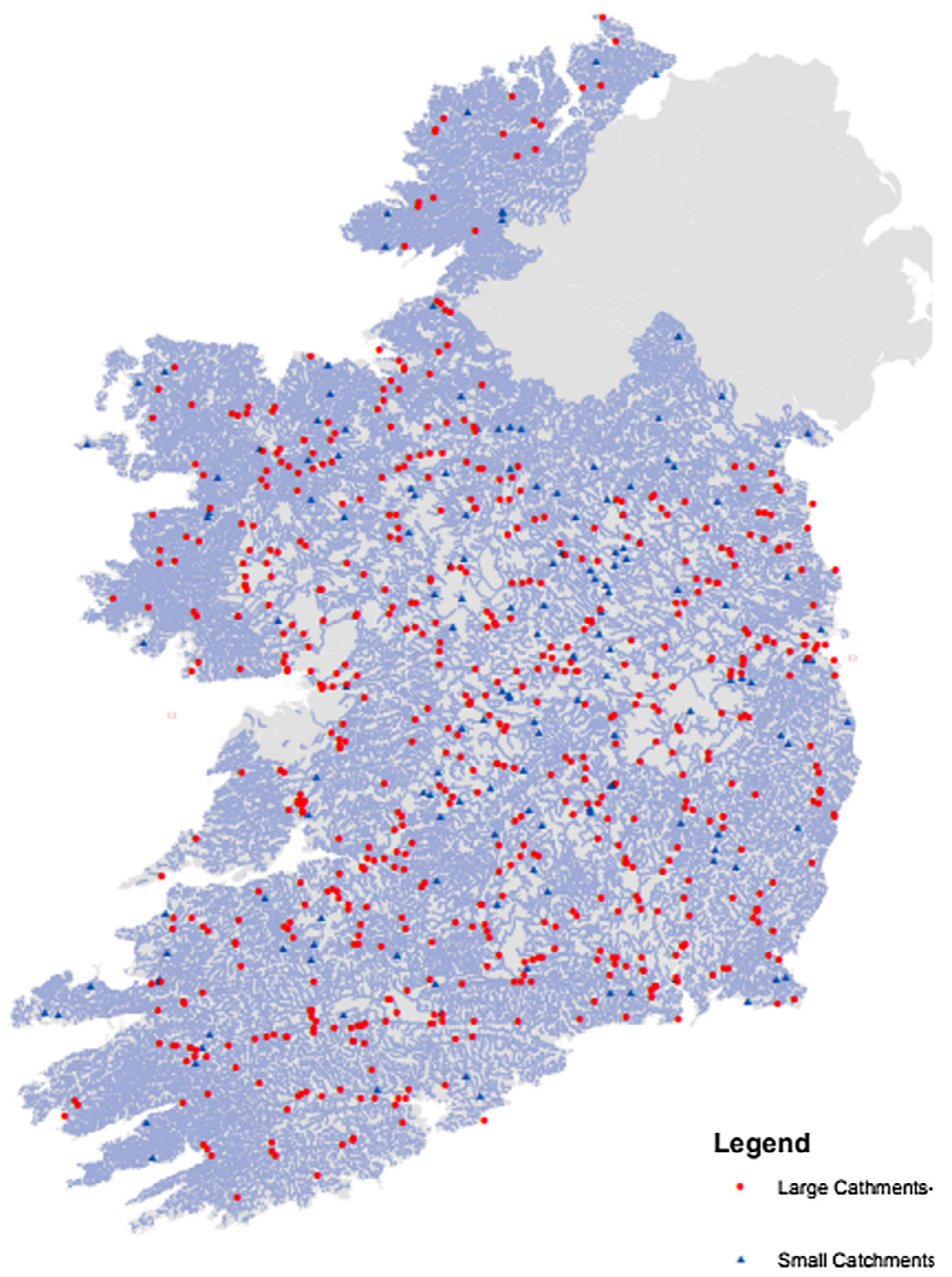

Fig. 1. Current Irish (RoI) operational hydrometric network of the Republic with large ( $\left.>30 \mathrm{~km}^{2}\right)$ and small $\left(<30 \mathrm{~km}^{2}\right)$ monitored catchments shown.

example, to comply with SI 272 of 2009 (European Communities Environmental Objectives (Surface Waters) Regulations 2009), regulatory authorities require mass balancing of existing discharges to receiving waters, thus necessitating data pertaining to low flow regimes in the receiving water, and particularly 95th percentiles and low flows (DWF).

Recognition of the fundamental importance of hydrometric monitoring, in addition to hydrometric and technological (i.e. digital recording, information technology) developments resulted in a widespread expansion of national hydrometric networks during the second half of the 20th century (Rodda, 1997; Mishra and Coulibaly, 2009; Hannah et al., 2011). However, recent studies report that decreased funding and changing governmental priorities have resulted in hydrometric network contractions in many regions over the past two decades (Grabs, 2009; Mishra and Coulibaly, 2009; Hannah et al., 2011). Moreover, concerns exist with respect to appropriate commercial and academic data usage and (transboundary) exchange, in addition to the compatibility and extent of existing hydrometric datasets (Grabs, 2009; Viglione et al., 2010). These issues are undoubtedly magnified due to enhanced data demands and increased financial pressures on network managers, thus requiring new approaches to optimising the societal benefits and overall efficacy of hydrometric information. Multiple studies have sought to optimise hydrometric networks using a variety of approaches including soft computing (e.g. fuzzy logic, machine learning, evolutionary computation), artificial intelligence, geostatistical analyses and indices development. For example, Werstuck and Coulibaly (2017) have recently employed a dual entropy multi-objective optimization (DEMO) method in the Ottawa River Basin to identify optimal locations for new hydrometric stations with some success.

To date, few studies have sought to comprehensively gather and analyse the perceptions and requirements of network data users and managers, and thus permit integration of user-based evidence into hydrometric network planning, management, optimisation, and policy. Based on a scoping study of the international literature, no similar assessment of hydrometric network expert opinion has previously been undertaken. Accordingly, the current study employed a quantitative questionnaire-based expert elicitation approach to realise three distinct 
research objectives, as follows:

Collate, analyse and assess hydrometric network manager and hydrometric data user opinions, knowledge, and experiences to identify current usage patterns, perceived network strengths, requirements, and limitations,

Quantify perceived (self-reported) network efficacy, and,

Provide a transferable baseline for future studies investigating hydrometric networks, programmes, and data.

\section{The Irish hydrometric network}

Hydrometric monitoring in Ireland dates to the early 20th century, with formalised network organisation initiated in the early 1940s. The current network is considered to have good spatial coverage, having been driven by arterial drainage works, electricity generation, infrastructural development and warning and control of extreme events (MacCárthaigh, 2002). Both the Environmental Protection Agency (EPA) and Office of Public Works (OPW) are responsible for hydrometric data measurement. The Environmental Protection Agency Local Authority (EPA-LA) hydrometric network was originally established in response to the 1976 drought event experienced in Ireland and the UK, which highlighted the need for closer monitoring of (low) river flows for sustainable water provision (Murphy et al., 2013). While the primary catalyst associated with the EPA-LA network was low flow monitoring, the major driver originally underpinning the OPW network was (and to an extent, continues to be) flood-risk management (i.e. flood monitoring, arterial drainage and development of early warning systems), and as such, OPW stations have been more frequently installed in larger catchments.

According to a recent review of the Irish hydrometric network (Nasr and Hynds, 2017), a total of 2385 currently or previously monitored catchments comprise the (active and inactive) network, with 957 catchments being actively monitored as of early 2017 (Fig. 1). Automated (continuous) recorder stations are employed in $99.3 \%(n=950)$ of actively monitored catchments, with the remainder comprised of staff gauging $(n=7)$. Surface water discharges $(Q)$ are measured at $58.5 \%(n=560)$ of monitoring stations, with water levels $(m)$ recorded at the remaining $41.5 \%(n=397)$. River catchments predominate the active network ( $\mathrm{n}=711,74.3 \%)$, followed by lake catchments $(\mathrm{n}=82$, $8.5 \%)$, drains/canals $(\mathrm{n}=73,7.6 \%)$, and (semi-)tidal catchments ( $\mathrm{n}=61,6.4 \%$ ). The mean monitored catchment area is $336.4 \mathrm{~km}^{2}$, ranging from $0.1 \mathrm{~km}^{2}$ to $8808.7 \mathrm{~km}^{2}$.

\section{Methods}

\subsection{Expert selection}

The authors have designed their study protocol based upon common elements from previous elicitation studies relating to environmental and infrastructural assessment (Knol et al., 2010; Fiorese et al., 2013; Truong and Heuvelink, 2013). Within the context of expert elicitation, it is important to clearly define the roles of "expert" and "manager", with experts classified based upon their expertise, while managers are inter alia involved in decision-making (Drew and Perera, 2012). Accordingly, throughout the current study, "expert" refers to survey respondents in possession of specialized, working knowledge of the Irish hydrometric network (i.e. research, practise, or both). Conversely, "managers" are characterised as respondents with the authority to influence processes and/or actions pertaining to the national hydrometric network. A list of expert and managerial groups employed for participant recruitment is presented in Table 1.

\subsection{Survey design}

Due to the typically low costs, high level of anonymity, ease of
Table 1

Expert and managerial groups employed for participant recruitment.

\begin{tabular}{ll}
\hline Experts (Data Users) & Managers (Decision Makers) \\
\hline National Roads Authority Employees & Office of Public Works Employees \\
Met Eireann Employees & $\begin{array}{l}\text { Emvironmental Protection Agency } \\
\end{array}$ \\
Inland Fisheries Employees & Electricity Supply Board Employees \\
Waterways Ireland Employees & Marine Institute Employees \\
Geological Survey of Ireland & Local Authorities (County Council) \\
$\quad$ Employees & Employees \\
IAH (Irish Chapter) Members & \\
Teagasc Employees & \\
National Parks and Wildlife Employees & \\
COFORD Employees & \\
ESAI Members & \\
ACIE Members & \\
$\quad$ Hydrological Researchers & \\
\hline
\end{tabular}

Notes: IAH - International Association of Hydrogeologists); ESAI Environmental Association of Ireland; COFORD - Competitive Forestry Research for Development, Department of Agriculture, Food and the Marine, ACIE - Association of Consulting Engineers of Ireland; Teagasc - Agriculture and Food Development Authority.

standardisation and completion, and relatively high response rates associated with online surveying (Dillman, 2000; Naughton and Hynds, 2013), this method was employed in the current study. The survey was developed offline using the SurveyMonkey (www.surveymonkey.net) survey design application. Active surveying took place over a threemonth period from mid-December 2015 - mid-February 2016. Initial contact (including the active survey link) was made with potential respondents in mid-December 2015, followed by monthly reminders in early January and February, with the survey taken offline on February 12th, 2016. The on-line surveying tool was configured to exclude IP addresses from data collation or storage, thus complying with current data protection standards (www.dataprotection.ie). No financial reward was offered to respondents. Due to the nature of the target audience and the non-personal nature of the questionnaire, formal written consent was not considered necessary, with a positive response deemed adequate evidence of consent.

A cross-sectional questionnaire entitled "The Hydrometric Network in Ireland: Uses, Efficacy, Strengths and Improvements" was developed for expert elicitation. A 10-12-min mean completion time and 30 question maximum were targeted during development to increase response rates, minimise response bias and thus maximise data quality (Hardigan et al., 2016). The final survey comprised 28 questions, including dichotomous $(n=1)$, open-format $(n=3)$, sole-response multiple choice $(n=12)$, relevance-based multiple choice $(n=6)$ and ranking/ordinal $(n=5)$ style questions. The questionnaire was delineated into four sections: (i) Respondent Profile, (ii) Hydrometric Network and Data Usage, (iii) Hydrometric Network Efficacy, and (iv) Hydrometric Network Requirements and Improvements. The final questionnaire draft was piloted (pre-tested) with 21 respondents in order that all language, questions, and overall framing/structure were adjudged suitable for use (i.e. optimisation of internal validity). The final questionnaire was revised through three iterations of feedback from two pilot runs until consensus was achieved. To avoid analytical bias and conform to best practise, responses and respondents associated with pilot studies were excluded from analyses.

Internationally, hydrometric monitoring is increasingly focusing on larger catchments and river basins, resulting in decreased data availability and modelling capabilities with respect to smaller (often flashier) catchments (Nasr and Hynds, 2017). Thus, catchment size was delineated and included in a number of survey questions. Previous hydrological studies of small catchments carried out in Ireland and the UK have typically defined and examined catchments of $\leq 30 \mathrm{~km}^{2}$ (e.g. Gebre and Nicholson, 2012). Accordingly, the same $\leq 30 \mathrm{~km}^{2}$ classification cut-off was employed in the current study. 


\subsection{Statistical analyses}

\subsubsection{Bivariate analyses}

All collated data were exported to MS Excel 2016, with data formatting, filtering, cleaning, and development of derived (dummy) variables carried out using conditional formatting and developed macros. Respondents were categorised based upon (a.) level of experience with hydrometric network data (Classification value: 5 years i.e. $<5$ years $=$ less experienced; $\geq 5$ years $=$ experienced), and (b.) expert/manager classification (See Table 1). All bivariate analyses were undertaken within the $\mathrm{R}$ statistical environment, using the FactoMineR, compareGroups and $M V N$ sub-packages. Odds ratios (OR) and associated 95\% CIs were used to examine levels of association between dichotomous $(2 \times 2)$ variable pairs. Pearson chi-square $\left(\chi^{2}\right)$ tests of independence were used to determine the presence of associations between categorical (dichotomous (2) or $(>2)$ nominal) variable pairs. Independent samples t-tests ( $\mathrm{t}$ ) (difference of means with equal variance assumed) were used to test for the presence of associations between dichotomous and continuous variables, with one-way analysis of variance (ANOVA) used to test for relationships between continuous variables and categorical variables with $>2$ levels of classification ( $F$ statistic). Spearman's non-parametric measure of rank correlation $\left(R_{\mathrm{sp}}\right)$ was used to examine relationships between continuous variables with non-linear distributions, and the Mann Whitney $U$ test was employed for assessing association between ordinal (ranked) and categorical variables. A statistical significance of $p<0.05$ has been used by convention.

\subsubsection{Multivariate analyses}

Multivariate modelling of respondent-reported "network efficacy" was undertaken using hierarchical logistic regression (HLR) with stepwise parameter entry (Forward Conditional). Variables were entered based on their bivariate correlation with the binary response variable (i.e. network adequate $\mathrm{Y} / \mathrm{N}$ ) with variable entry taking place at $p=0.05$ and removal at $p=0.1$. A maximum of 20 estimation iterations were run for each model step, with estimation terminated where parameter estimates changed by less than 0.001 between two estimation iterations. Variable collinearity was evaluated within HLR models using the variance inflation factor (VIF). Variables with a low tolerance statistic $(<0.7)$ contribute little additional information to the model, and were subsequently removed.

\section{Results}

\subsection{Respondent profile}

In all, 203 respondents participated, of which $67.2 \%$ were male. Most respondents were categorised within the $30-40$ year $(33.7 \%)$ and $40-50$ year $(28.2 \%)$ age brackets, with responses acquired from 28 of 32 administrative Irish counties; counties Dublin (28.4\%), Cork $(13.2 \%)$ and Galway $(8.8 \%)$ were the most frequently represented. Overall, 4.9\% $(n=10)$ of respondents resided outside of Ireland, but had previously worked with Irish hydrometric data. Self-reported respondent professions, areas of professional expertise, professional experience, and expert/manager classification are presented in Fig. 2.

"Experienced" ( $>5$ years) respondents had an average of 16.7 years previous experience working in hydrological science, while less experienced respondents ( $<5$ years) reported a mean of 2.4 years, with an overall sample mean of 11.1 years (Std. Dev 9.18, Min 0.25, Max 45). One third $(34.1 \%)$ of less experienced $(<5$ years) respondents were employed in hydrological research, compared with $14.1 \%$ of experienced respondents. A significantly higher proportion of experienced respondents (27.3\%) were employed in governmental agencies than was the case among less experienced respondents (9.1\%). Similarly, a higher proportion of experienced respondents were classified as "managers" (46.6\%) than was encountered among less experienced respondents $(13.8 \%)\left(\chi^{2}(1)=16.865, \mathrm{p}<0.001\right)$.

\subsection{Hydrometric data usage}

Altogether, $52.3 \%$ of respondents reported current (within the last month) hydrometric data use, with the remainder (47.7\%) reporting usage within the last two years. Overall, $43.3 \%$ of respondents reported sporadic (annual or less than annual) data usage, with $32.3 \%, 17.3 \%$, and $7.1 \%$ of those surveyed typically utilising data on a monthly, weekly, and daily basis, respectively. Some level of association existed between frequency of use and self-reported hydrological experience ( $>/<5$ years), however, albeit not at a 95\% confidence level $\left(\chi^{2}(4)=8.811, \mathrm{p}=0.066\right)$; frequent usage (daily/weekly) was evenly distributed among both categories, however more experienced users were more likely to report infrequent usage. In all, $71.2 \%$ of respondents reported that they download the most recently updated data on a site- or catchment-specific basis as required, while $19.8 \%$ employ previously acquired (cached) data; less frequent users were more likely to employ cached data $\left(\chi^{2}(16)=30.465, \mathrm{p}=0.016\right)$.

Of those respondents whose professional work typically focused on one hydrological catchment size, $51 \%, 29 \%$ and $17.6 \%$ indicated that their work concentrated on small catchments $\left(<30 \mathrm{~km}^{2}\right)$, large catchments $\left(>30 \mathrm{~km}^{2}\right)$, and larger hydrological basins $\left(>1000 \mathrm{~km}^{2}\right)$, respectively. Experienced users ( $>5$ years) were over twice as likely to employ small catchment data (OR 2.066, 95\% CI 1.085-3.921), while network managers were significantly more likely to use data from larger hydrological basins $\left(\chi^{2}(1)=3.801, \mathrm{p}=0.043\right)(\mathrm{OR} 2.318,95 \%$ CI 1.085-3.921). Respondents whose work focused on larger catchments $\left(>30 \mathrm{~km}^{2}\right)$ were associated with significantly higher levels of usage frequency $\left(\chi^{2}(4)=11.854, p=0.018\right)$. Sub-daily (15-min intervals) (44\%) and daily (43.1\%) data were the most frequently employed data resolutions (Fig. 3a).

River (54.4\%), urban (19.6\%), and tidal (18.1\%) catchment data were the most frequently accessed and employed (Fig. 3b); where respondents only indicated the use of data from one catchment type, river catchments represented a significant majority (83.8\%), thus reflecting current network composition (Section 2). Respondents whose work focuses on river catchments were categorically more experienced $\left(\chi^{2}(1)=11.619, \quad \mathrm{p}=0.001\right), \quad$ used data more frequently $\left(\chi^{2}(4)=32.377, \mathrm{p}<0.001\right)$, were more likely to employ recently updated data $\left(\chi^{2}(4)=13.492, \mathrm{p}=0.009\right)$, and more likely to utilise high resolution (sub-daily) data $\left(\chi^{2}(4)=19.136, \mathrm{p}=0.001\right.$ ).

Water level (m) (37.3\%), discharge $\left(\mathrm{m}^{3} / \mathrm{sec}\right)(34.3 \%)$, and summary hydrological statistics $(32.4 \%)$ were the most frequently employed hydrometric variables among surveyed users (Fig. 3c). Where just one variable was utilised, water level data (41.9\%) remained the most frequently utilised, followed by summary statistics (30.2\%), discharge (18.6\%), and instantaneous data (7\%). A significantly greater proportion of "experienced" network users ( $>5$ years) reported use of instantaneous hydrometric data $\left(\chi^{2}(1)=5.738, p=0.017\right) ; 81.1 \%$ of instantaneous data users had $>5$ years of hydrological experience. Instantaneous data were strongly associated with small catchment studies $\left(\chi^{2}(1)=5.196, p=0.023\right) ; 94.6 \%$ of respondents reporting current or previous work in small catchments used instantaneous data. Survey participants that reported using up to date hydrometric data were more likely to employ discharge $\left(\chi^{2}(4)=11.765, \mathrm{p}=0.019\right)$ data, as were those who characterised themselves as "current users" $\left(\chi^{2}(2)=10.960\right.$, $\mathrm{p}=0.004)$. Usage frequency was also associated with the use of discharge data $\left(\chi^{2}(4)=14.531, p=0.006\right)$, for example, $72.8 \%$ of respondents reporting at least monthly hydrometric data usage (i.e. daily, weekly, or monthly) employed discharge data, with an equivalent figure of $41.2 \%$ among more sporadic users (< monthly). Conversely, respondents that typically employed previously acquired (i.e. less current) data were more likely to employ instantaneous measurements $\left(\chi^{2}(4)=10.523, p=0.032\right)$. 


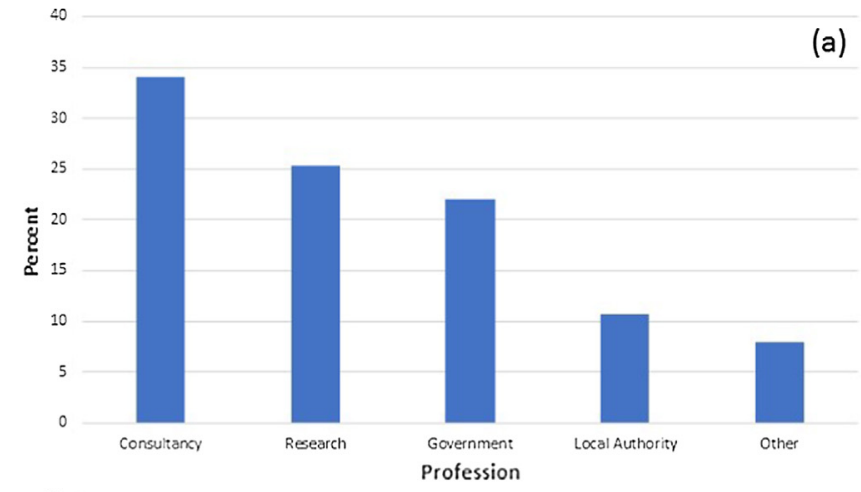$$
\text { ss }
$$

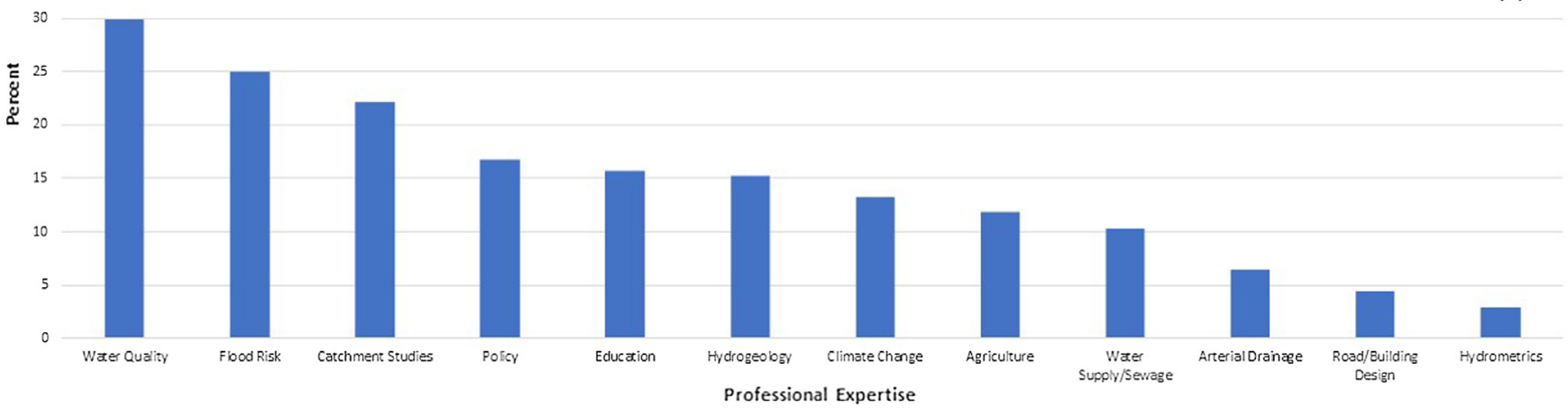

(b)

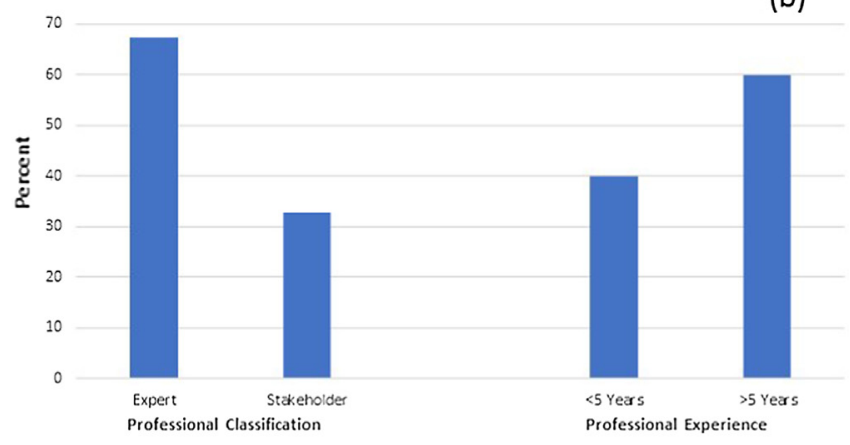

(c)

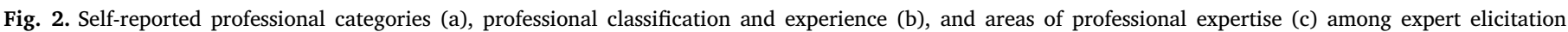
participants.
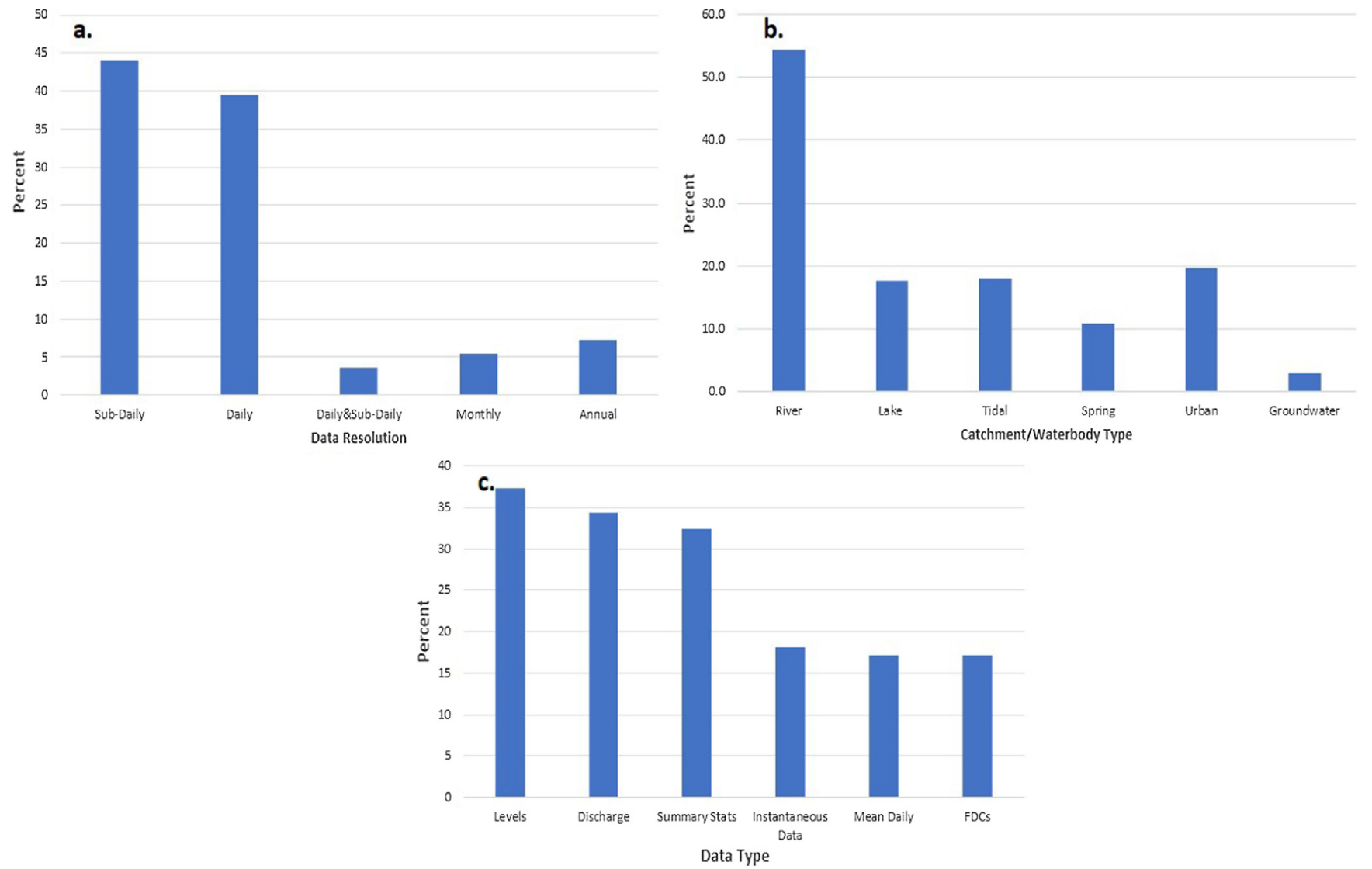

Fig. 3. Self-reported data usage among respondents in terms of (a) data source (b) catchment/waterbody type, and (c) data type. 


\subsection{Network efficacy}

Just over half $(50.5 \%)$ of surveyed network users indicated that the network is currently inadequate, with a further $8.5 \%$ reporting that efficacy is highly local or station-dependant; $32.4 \%$ believe that the network is currently adequate. Neither hydrological experience $(p=0.188)$ nor expert/manager classification $(p=0.368)$ were associated with perceived levels of efficacy. Previous users were over twice as likely (OR 2.243; 95\% CI 1.002, 5.390) than current users to classify the current network as being adequate for their professional requirements $\left(\chi^{2}(6)=16.261, p=0.012\right)$. Network efficacy was not statistically associated with a particular data type, source, or usage pattern (p > 0.05)

A significant majority (81.9\%) of respondents stated that missing hydrometric data (i.e. incomplete time series) had represented a limitation during their professional work, with these respondents significantly more likely to attribute a low level of efficacy to the network and associated data $\left(\chi^{2}(2)=8.404, p=0.015\right)$. While $29.2 \%$ of respondents associated with previous data issues noted that the current network was adequate, an equivalent figure of $77.8 \%$ was found among those not previously experiencing data limitations. Missing data were reported as having previously occurred among $82.1 \%$ (small catchments) to $86 \%$ (large hydrological basins) of data users, with highest levels of missing data attributed to urban catchments (85.7\%). The issue of missing data was not statistically associated with any specific data type, source, or usage pattern $(p>0.05)$

Most respondents reported that overall hydrometric network efficacy had improved $(53.2 \%)$ or remained unchanged $(26.6 \%)$ over the course of their professional career, while $13.8 \%$ reported a decline (Fig. 4). A significant difference was found between experts perceived network efficacy and their level of hydrological experience $\left(\chi^{2}(3)=11.956, p=0.008\right)$, with experienced users more likely to report a notable (upward or downward) shift in temporal network efficacy. As shown (Table 2), a low level of efficacy was attributed to both current network density (33.8\%) and network representivity (33.3\%), with neither indicator significantly associated with catchment size (i.e. poor ranking independent of catchment scale). Level of respondent experience was associated with ranking of network data availability $\left(\chi^{2}(2)=7.396, \quad p=0.025\right), \quad$ network density $\left(\chi^{2}(2)=12.626\right.$, $\mathrm{p}=0.002)$, and network representivity $\left(\chi^{2}(2)=6.889, \mathrm{p}=0.032\right)$ (Table 2), with lower levels of satisfaction exhibited by more experienced users in all cases.

The final HLR model had a mean prediction accuracy of
Table 2

Ordinalised "level of efficacy" attributed to the current hydrometric network indices by expert elicitation respondents $(\mathrm{n}=203)$

\begin{tabular}{llll}
\hline Network Index & High (\%) & Moderate (\%) & Low (\%) \\
\hline Data Quality & 33.3 & 59.1 & 7.5 \\
Data Availability & 20.4 & 59.1 & 20.4 \\
Data Formatting & 23.6 & 61.8 & 14.6 \\
Network Density & 7.5 & 58.8 & 33.8 \\
Network Representivity & 9.9 & 56.8 & 33.3 \\
\hline
\end{tabular}

Table 3

HLR "Network Efficacy" Model Classification ( $\mathrm{n}=199)$.

\begin{tabular}{llll}
\hline & Observed & Predicted & Percent Correct \\
\hline Network Adequate & 72 & 51 & 70.8 \\
Network Inadequate & 127 & 118 & 92.9 \\
Total & & & 84.8 \\
\hline
\end{tabular}

Table 4

Final HLR Model for Respondent Reported Network Efficacy.

\begin{tabular}{llllll}
\hline & $\beta$ & $\beta$ Sig. & Model Sig. & H/L Sig & $\mathrm{R}^{2}$ \\
\hline $\begin{array}{l}\text { Hierarchy 1: User Traits } \\
\text { Data Usage (Currency) }\end{array}$ & -2.022 & 0.009 & & & \\
Urban Catchments & 1.559 & 0.035 & 0.009 & 0.185 & 0.183 \\
Hierarchy 2: Attribute Rating & & & & & \\
$\begin{array}{l}\text { Data Quality } \\
\text { Network Density }\end{array}$ & -1.604 & 0.023 & & & \\
\end{tabular}

Here $\beta$, regression coefficient; $\beta$ Sig., regression coefficient significance; Model Sig., significance of hierarchy within overall model (cumulative); H/L Sig., significance of Hosmer-Lemeshow goodness of fit diagnostic ( $p>0.05) ; R^{2}$, Nagelkerke coefficient of determination (cumulative).

approximately $85 \%$, with a particularly high level of predictive accuracy associated with perceived network inadequacy (92.9\%) (Table 3). As shown (Table 4), two significant hierarchies (model blocks) were found, namely network user traits (Model Significance $=0.009,18.3 \%$ of variance) and network attribute ratings (Model Significance < $0.001,38.9 \%$ of variance). Respondents currently using network data and urban catchment data were significantly more likely to report network inadequacy. Data quality and network density were the individual attributes most strongly associated with overall network

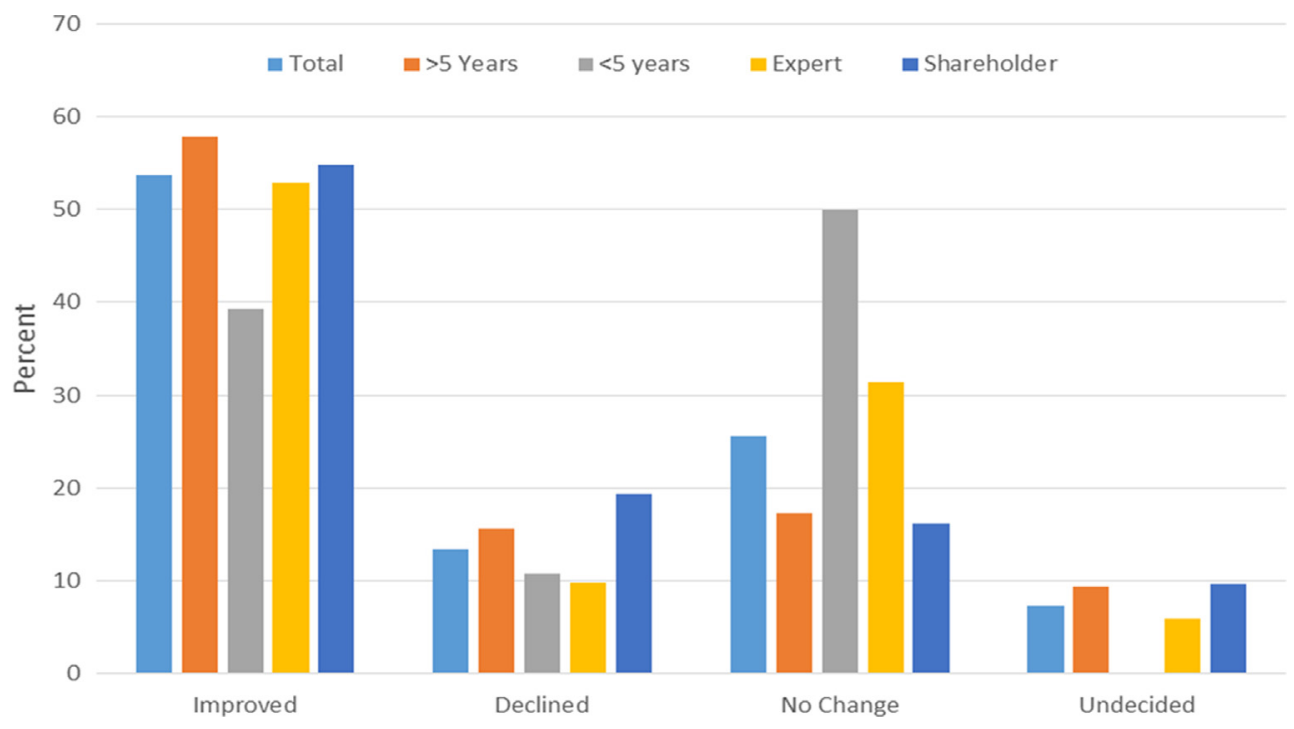

Fig. 4. Respondent reported changes in hydrometric network efficacy stratified by respondent experience and expert/shareholder classification. 


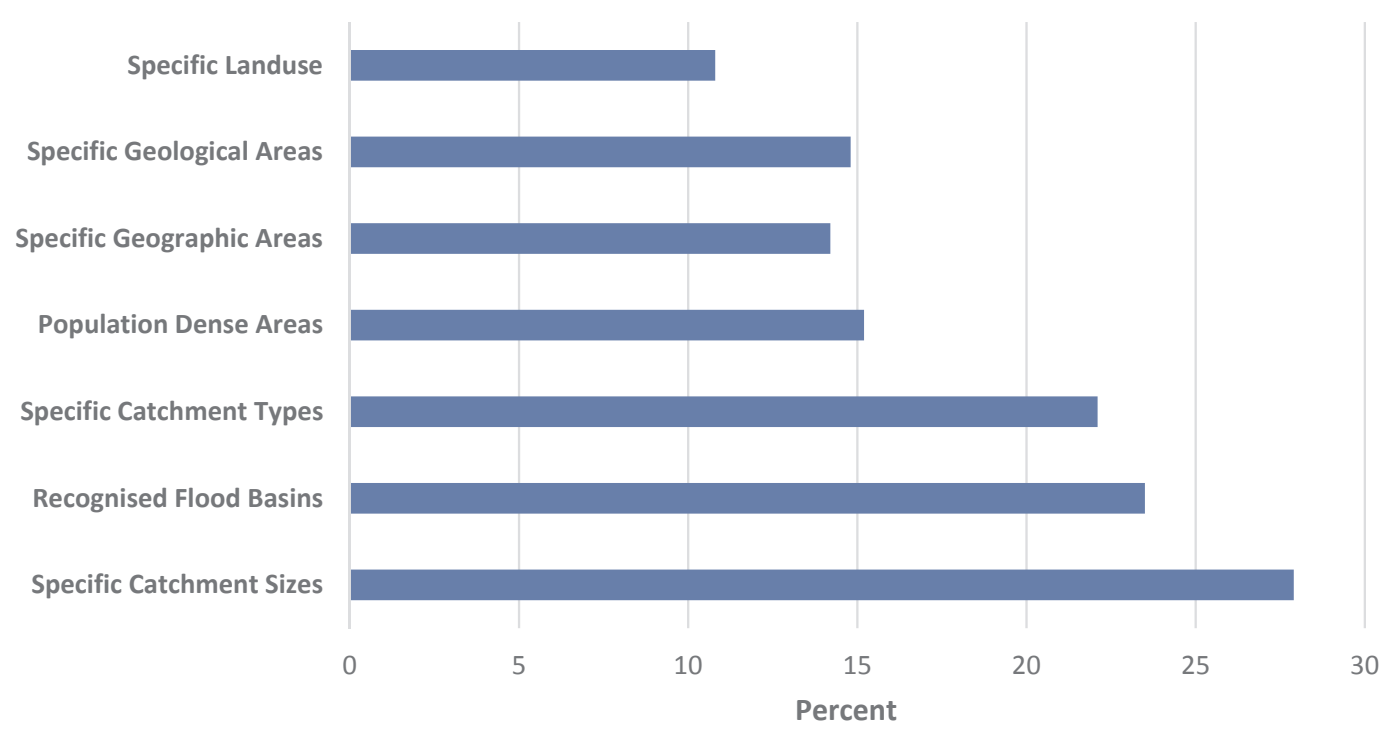

Fig. 5. Prioritised categorical areas for future hydrometric network density increases in the Republic of Ireland.

efficacy.

\subsection{Network optimisation}

Overall, $85.4 \%$ of experts agreed that network density should be amended as a priority, of which $60.2 \%$ favoured focused network density increases (i.e. specific catchment types, catchment sizes, geographical areas, etc.), and the remaining $39.8 \%$ reported a preference for a "generalised" (i.e. national) network density increase. As shown (Fig. 5), catchment size (27.9\%), flood prone areas $(23.5 \%)$, and catchment (waterbody) type (22.1\%) were the most frequently selected catchment attributes on which to base network density increases.

When asked to identify and rank which hydrometric and climactic variables require optimisation to maximise overall network utility, river discharge (i.e. continuous flow recording) (34.1\%) and water level (i.e. river stage) (33.3\%) were most frequently selected (Fig. 6).
Respondents characterised by lower levels of professional experience were more likely to prioritise an increase in groundwater level measurements $\left(\chi^{2}(5)=12.021, p=0.035\right)$. A higher proportion of network data users $(22.2 \%)$ prioritised improved rating curves than network managers $(12.0 \%)$, however this was not significant at a $95 \%$ level $(\mathrm{p}=0.060)$.

To further explore the perception of "network efficacy", respondents were asked to rank (high, moderate or low) several "resilience indicators" for improving overall levels of utility associated with the current hydrometric network and data. As shown (Table 5), highest levels of importance were attributed to data centralisation $(65.5 \%)$, increasing representivity (i.e. appropriate proportions of catchment types and sizes) via focused network amendments (61.2\%), and increasing the number of gauged small catchments $(60.2 \%)$. The only listed resilience indicator significantly associated with perceived network adequacy was small catchment network density $(\mathrm{p}=0.045)$.

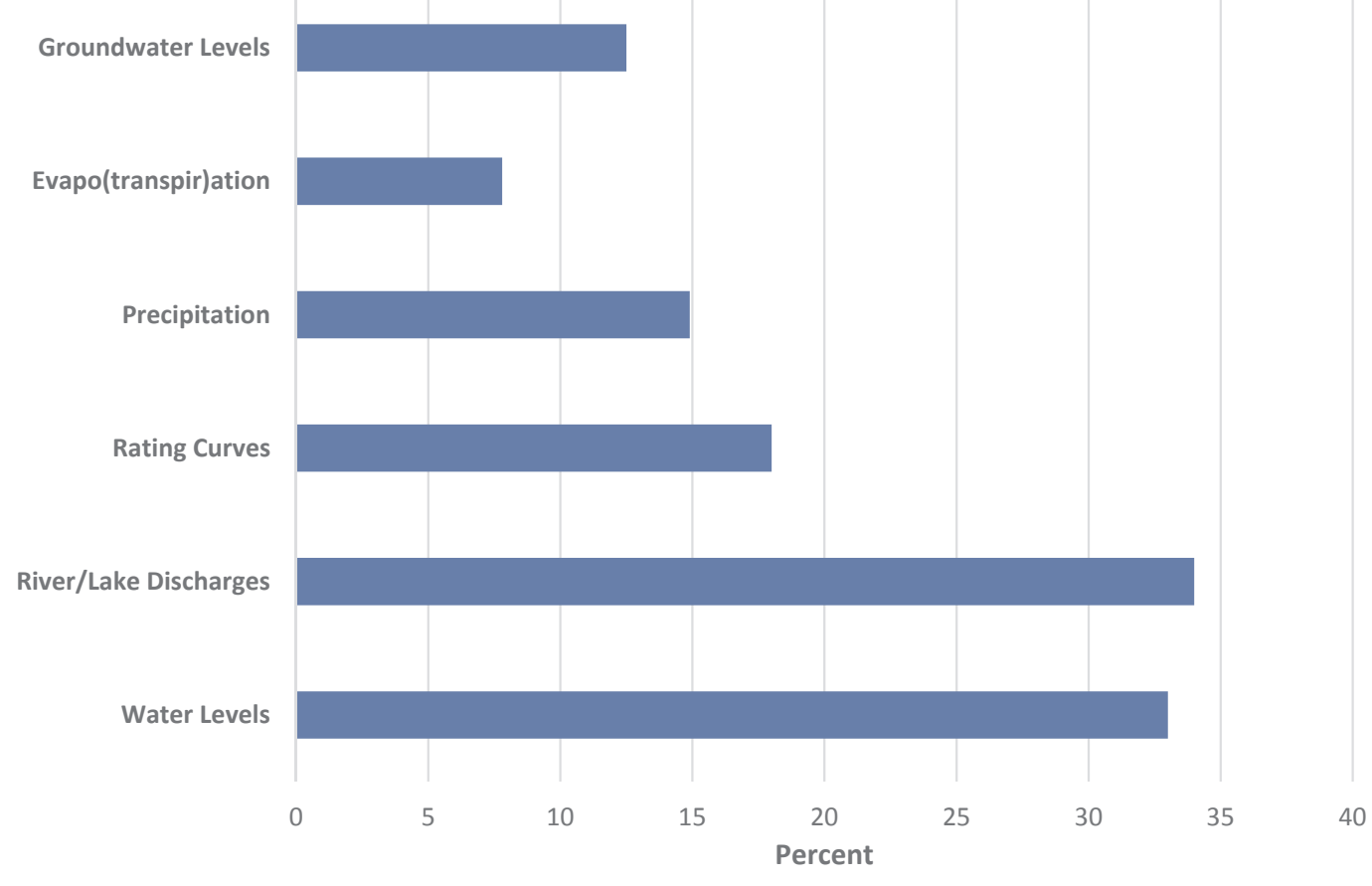

Fig. 6. Hydrometric/climatic variables requiring amendment for increasing hydrometric network resilience/efficacy. 
Table 5

Prioritised amendments and respondent-matched association with perceived network efficacy.

\begin{tabular}{|c|c|c|c|c|}
\hline \multirow[t]{2}{*}{ Efficacy Indicator } & \multicolumn{3}{|l|}{ Priority } & \multirow[t]{2}{*}{ Association with Network Efficacy } \\
\hline & High (\%) & Moderate (\%) & Low (\%) & \\
\hline Record Periods & 33.7 & 47.7 & 17.4 & 0.926 \\
\hline Data Accuracy & 38.4 & 39.5 & 19.8 & 0.292 \\
\hline Network Representivity & 61.2 & 31.8 & 4.7 & 0.455 \\
\hline Network Density & 58.9 & 32.2 & 6.7 & 0.588 \\
\hline Small Catchment Monitoring & 60.2 & 26.1 & 12.5 & 0.045 \\
\hline Large Catchment Monitoring & 43.5 & 40.1 & 14.1 & 0.775 \\
\hline Data Centralisation (Availability) & 65.5 & 24.1 & 5.7 & 0.161 \\
\hline Data Formatting & 34.1 & 34.1 & 28.2 & 0.423 \\
\hline
\end{tabular}

* p-value associated with Mann Whitney $U$ test.

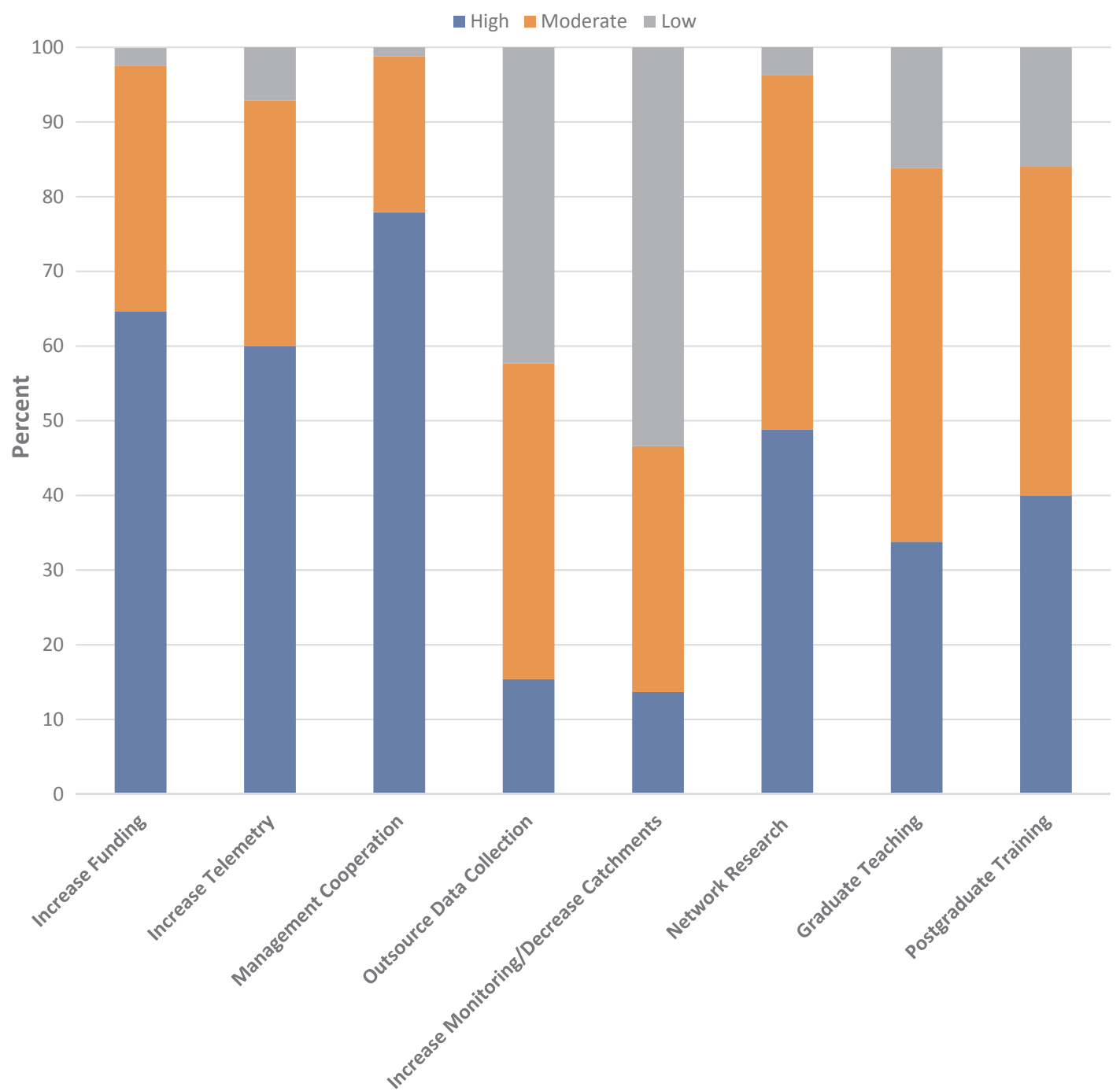

Fig. 7. Prioritised general organisational amendments for increased future network efficacy and resilience.

Finally, respondents were asked to prioritise general organisational amendments for increased future network efficacy and resilience in terms of changing climate, landuse, and residential patterns (Fig. 7). As shown, highest levels of priority were ascribed to management cooperation (77.9\%), funding (64.6\%) and the use of telemetry $(60.2 \%)$. No statistically significant associations were found between respondent prioritisation (Table 5) and respondent-matched network efficacy. However, a significant difference was found between respondent classification (expert/manager) and prioritisation of data collection outsourcing (Mann Whitney $\mathrm{U}=247.5, \mathrm{p}=0.001$ ), with experts approximately 10 times more likely than network managers to allocate high levels of importance to outsourcing.

\section{Discussion}

The current study sought to elicit the experiences, opinions and requirements of Irish hydrometric data users and managers to develop evidence-based recommendations, realisable within the context of current resources, and permit an increasingly proactive and qualitative approach to future proofing hydrometric networks. 


\subsection{Redefining users needs}

Accommodation of user needs should be at the forefront of hydrometric network design; providing an efficient and accurate data repository which allows for rapid and precise interpretation across multiple sectors. The diversity of users has increased in recent years, with consultants (34\%), academic researchers $(25.3 \%)$ and government agency employees (22\%) comprising the majority of the population $(n=203)$ surveyed in this study. Within these sectors, myriad areas of expertise, and thus data requirements were identified, with water quality (29.9\%), flood risk management (25\%), catchment studies (22.1\%), and education or research (15.2\%) comprising the primary focus areas, demonstrating a shift towards legislative compliance and water quality research, thus mirroring global trends (Cassidy and Jordan, 2011). In line with this, a shift in user profile patterns was also identified with a significant proportion of "less experienced" $(<5$ years) respondents employed through hydrologic consultancies and academic research identified as network users. These 'new' users frequently reported requiring up-to-date data, while in contrast, more experienced users utilise hydrometric data less frequently, tend towards using cached data and are more likely to require flow duration curves, perhaps due to natural career progression into project management and supervision. The disparity of user needs across user groups is a common trend throughout this study, suggesting that there is an increasing need for a dynamic hydrometric network which can provide multi-modal data collation and extraction in line with evolving user needs. The authors consider that without a move away from a homogenised data needs model, the potential for hydrometric data applications may stagnate, further reducing network efficacy into the future.

For example, focusing on specific data needs and interaction, small $\left(<30 \mathrm{~km}^{2}\right)$ catchment data are most frequently employed in the Republic of Ireland, with over half of respondents working exclusively with these data. However, in spite of the high demand, the small catchment network in RoI has contracted significantly over the past two decades, with the current network focusing principally on large catchment monitoring (Nasr and Hynds, 2017) (Fig. 1). This trend of reduced or constricted hydrometric monitoring is not indigenous to Ireland and has been reported globally; indeed, hydrometric monitoring has declined worldwide over the past three decades, representing a concern when viewed within the context of widespread climate and land use changes, with experts consequently less equipped to monitor water supplies and forecast hydrological extremes (Mishra and Coulibaly, 2009; Hannah et al., 2011).

\subsection{Perceived network efficacy}

Overall, a general level of dissatisfaction among hydrometric data users in the RoI was noted with $50.5 \%$ of surveyed network users indicated that the network is currently inadequate and a further $8.5 \%$ reporting that efficacy is highly localised or station-dependent. Moreover, results from this study demonstrate that a significant association exists between hydrological experience and perceived network efficacy ( $p=0.008$ ), with network user traits also associated with reported network limitations and inadequacies (Table 4). Previous (as opposed to current) data users were over twice as likely (OR 2.243) to classify the network as being adequate for their professional requirements ( $\mathrm{p}=0.012)$, further reiterating the importance of redefining user needs on an ongoing basis. As current and less experienced professionals are largely "non-managerial" users, i.e. researchers, academics and consultants, they have significantly different data/usability requirements, requiring consideration and periodic evaluation. Of note, one such difference is the application of increasingly complex catchment modelling to hydrological issues, for which data requirements vary significantly depending on modelling objectives and catchment type. For example, modelling of large-scale rural catchments typically requires extensive spatial monitoring to obtain representative data describing the physical settings within the catchment. Conversely, while temporal resolution is undoubtedly a critical concern for modelling all catchments, previous studies have shown it is a particular issue when modelling small urban catchments to appropriately capture hydrodynamic behaviours (Kannan et al., 2007; Kalantari et al., 2014). Additionally, specific causative factors of perceived inefficiency or inadequacy were identified, with respondents who had previously encountered missing data (81.9\%) almost 5 times more likely to exhibit dissatisfaction with the network. Likewise, inadequate network density and network representivity with respect to both catchment type and spatial distribution were also associated with a perceived lack of network resilience. Multivariate modelling of network efficacy at the individual level indicated that network user traits (professional demographic) (Hierarchy 1) and perceived network attributes (Hierarchy 2) combined to correctly predict $85 \%$ of surveyed respondent's perceptions, with network attributes accounting for $68 \%$ of variance within the model (i.e. predictive significance). This lack of consistency across networks is particularly problematic in terms of accuracy and will inevitably increase the error and uncertainty associated with regional streamflow predictions. For example, a study in the Mackenzie Basin in western Canada found that where stations were closed or non-comparable within a network, extrapolation error increased by $\sim 16 \%$ for all flow regimes (Spence et al., 2007). As such, no 'one size fits all' approach exists for data homogenisation or optimisation after hydrometric network design and/or closure and thus, moving forward, the involvement of key share/stakeholders in the (re)design stage is paramount to the sustainable optimisation and evolution of the hydrometric network.

\subsection{Towards an optimum hydrometric network}

An optimum hydrometric network has been defined by Bobrovitskaya et al. (2001) as "........achieved when the volume and quality of data collected and processed is economically justifiable and meets users' needs", with hydrometric network design and optimisation being gradual processes (Hannaford and Marsh, 2008; Mishra and Coulibaly, 2009; Hannah et al., 2011; Cox et al., 2014). This sentiment is mirrored within this study, whereby the three most pressing issues surrounding the Irish hydrometric network were: (1) Incorporation of a wider scope of user needs, (2) Increased hydrometric network density and (3) Multilevel management strategies and structures which facilitate an iterative process of optimisation.

\subsubsection{Incorporation of a wider scope of user needs}

Within this study, an overarching pattern was the existence of myriad definitions of hydrometric network efficacy, depending on respondents' personal experience and current requirements, thus emphasising the importance of stakeholder interaction for network optimisation. Indeed, the primary recommendation of this research is that consultations prior to network upgrading should include the opinions and requirements of a diverse group of hydrometric data users to ensure resilience, as well as user satisfaction. Moreover, recently qualified, less experienced users whose requests may outstrip those of more experienced managers and supervisors must be listened to and where possible, accommodated. As such, the authors consider it inappropriate to rely solely on the opinions of a small group of individuals, and particularly groups with shared data requirements (e.g. network managers) when designing or upgrading hydrometric networks, which has previously been done. Instead, a move towards the integration of both managers and non-managerial data users in the hydrometric network design process is paramount, and has shown to be effective elsewhere. For example, Pyrce (2004) reports that both the Grand River (Ontario) catchment and Ontario stream gauge rationalisation projects successfully prioritised stations using an auditing approach, whereby evaluations were based upon practitioner/user inputs. Indeed, the integration of user needs at the network conception stage not only permits wider 
data development, but also allows for change.

\subsubsection{Increased hydrometric network density}

Focusing on network density, the majority of hydrometric data users associate network density via increased station (re)activations with an improved and evolved hydrometric network, with $85.4 \%$ of experts agreeing that network density should be amended as a priority, while $60.2 \%$ favour focused network density increases. This is an important and clear finding of this study; an increase in network density allows for increased data generation and increased efficacy of the overall network. However, in order to achieve the greatest level of optimisation, spatial diversity is required- notably, approximately $27 \%$ of respondents prioritised network density increases within varying catchment sizes (i.e. small, large, basin), with a further $23.5 \%$ and $22.1 \%$ highlighting the need for network upgrades in flood prone areas and specific catchment (waterbody) types, respectively, thus indicating a shift towards long-term monitoring and modelling. In Ireland, 'benchmark' hydrometric stations have been selected for long term monitoring of river flows specifically for climate change assessment and mitigation (e.g. flood defence) (Murphy et al., 2013), however, these stations are primarily located in larger catchments. Conversely, the relative shortage of small stream monitoring data represents a fundamental obstacle to undertaking any rigorous investigation of the hydrodynamics of smaller catchments (Faulkner et al., 2012). Thus, a significant increase in small catchment network density is required to optimise the national network. Similarly, when asked to identify and rank which hydrometric and climactic variables require optimisation to maximise overall network utility, river discharge (i.e. continuous flow recording) (34.1\%) and water level (i.e. river stage) (33.3\%) were most frequently selected (Fig. 7), likely indicative of the lack of availability of these data in smaller catchments, but also perhaps relating to concerns surrounding climate change and associated events i.e. flooding. Respondents characterised by lower levels of professional experience were more likely to prioritise increased groundwater level measurements $(p=0.035)$ as an area for optimisation, suggesting increased usage of and requirements for groundwater data. The authors consider it likely that groundwater data quality requirements are associated with increasingly universal hydrological models and growing interest in the effects of climate and land use changes on groundwater quality/quantity and groundwater/surface water interactions (Kløve et al., 2014; Andrade et al., 2018).

\subsubsection{Multi-level management strategies and structures}

Management cooperation (77.9\%) and funding (64.6\%) were the most frequently cited organisational (i.e. non-design) issues requiring amendment, both of which are fundamental at the design stage and play an underpinning role in shaping network efficacy. Network funding is often predicated on the economic value attributed to hydrometric data, which is ultimately hard to quantify. The economic benefits of data collection are often not realised 'pre event', i.e. after a decision is made which could not have been undertaken in the absence of appropriate hydrometric data. Furthermore, the benefits of hydrometric data are often qualitative and intangible, for example, accurate economic assessment of compliance with statutory reporting requirements remain problematic Similarly, it is extremely difficult to calculate the value to an individual or community that benefits from pre-emptive flood warning (Walker et al., 2009). The authors consider that instead of focusing on the economic justification of an efficacious network, perhaps we should be vocal of the direct and indirect costs of an ineffective network, which may result in loss of property or lives (via network failure), a revenue and/or resource shortfall, or unforeseen adverse impacts on users (e.g. water logging, salinization, impacts on wetlands, lakes, floodplains, and estuaries) (Mishra and Coulibaly, 2009). Indeed, one mechanism to quell the notion that hydrometric monitoring is potentially economically unsustainable is to re-evaluate its importance at the global rather than national level, particularly under the auspices of a changing climate, which affects all nations. Moving forward, data users and hydrometric managers should consider global data agreements founded on the exchange of environmental information and international archives, which will strengthen the argument for optimisation of hydrometric networks. However, this shift from locally related to globally relevant requires hydrometric managers to rethink and re-evaluate how data can be utilised whilst circumventing the associated challenges of 'big data' storage, management and manipulation (Devia et al., 2015), all of which need to be incorporated into network design to ensure longevity and accuracy. Nevertheless, the internationalisation of hydrometric data opens the door to non-exchequer funding, which could provide a much needed catalyst to increase the volume and quality of data collected in an economically justifiable manner that meets multiple user needs; an optimal hydrometric network.

\subsection{Limitations}

As for any approach to data measurement and analyses, the authors that expert elicitation comprises several potential limitations which should be considered and accounted for including potential inaccuracy, overconfidence and subjectivity bias. Burgman et al. (2011) have reported that perceived level of expertise (i.e. qualifications, years of experience, track record) was not correlated with performance in terms of quantity, frequency or probability estimation. However, while expert elicitation is criticized in various aspects, such as selection of experts and accurate expression of experts' knowledge and belief in probability forms, the quality of expert judgment can be controlled by a formal procedure of expert elicitation and documentation (O'Hagan and Oakley, 2004). Every effort had been made to avoid bias or inaccuracy in the current study via elicitation of a significant sample of relevant experts and users, however, expert opinion should be used with caution, and should not replace 'hard' science.

\section{Conclusions}

Study findings indicate a significant shift away from "managerdriven" data usage to a more compliance-based, scientifically driven data approach. Less experienced professionals comprise a significant proportion of the hydrometric community and are characterised by increased data requirements due to the use of updated modelling software. Accordingly, their specific data requirements must be accounted for, and preferably at the design stage. Recommendations derived from the current study largely focused on cooperation and consultation between data users and network managers to develop a network capable of facilitating sustainable water resource management. However, it is important to note that future resilience and capacity building must be achieved through targeted approaches, with geographically distinct areas (flood prone, small catchments, high population densities, etc.) prioritised for development. Management (design, implementation) and funding (capital expense, time) are frequently cited as representing the primary impediments to network efficacy, thus, the importance of an 'integrated' approach whereby individual needs are also considered is most conducive to value for money and network integrity.

\section{Acknowledgement}

The authors wish to acknowledge the Environmental Protection Agency (Ireland) for funding this study (Grant Number 2014-W-DS-15).

\section{References}

Andrade, L., O'Dywer, J., O'Neill, E., Hynds, P., 2018. Surface water flooding, groundwater contamination, and enteric disease in developed countries: a scoping review of connections and consequences. Environ. Pollut in press.

Bobrovitskaya, N.N., Bestsennaya, M.A., Kokorev, A,V., Nedogarko, I.V., 2001. Research 
network and its data to estimate transboundary transfer of water, sediments and pollutants. In: Hydrological Challenges in Transboundary Water Resources Management. International Conference, Koblenz, Germany, 25-27 September 2001, pp. 201-205.

Burgman, M.A., Carr, A., Godden, L., 2011. Redefining expertise and improving ecological judgement. Conserv. Lett. 4, 81-87.

Cassidy, R., Jordan, P., 2011. Limitations of instantaneous water quality sampling in surface water catchments: comparison with near-continuous phosphorus time-series data. J. Hydrol. 405 (1-2), 182-193.

Cheng, G., Li, X., Zhao, W., Xu, Z., Feng, Q., Xiao, S., Xiao, H., 2014. Integrated study of the water-ecosystem-economy in the Heihe River Basin. Natl. Sci. Rev. 1 (3), 413-428.

Cox, J.P., Shaeri Karimi, S., Eslamian, S., 2014. Optimum hydrometric site selection. In: Eslamian, S., (Eds.) Handbook of Engineering Hydrology, Fundamentals and Applications, vol. 1. Francis and Taylor, CRC Group, USA, pp. 471-483 (Chapter 22).

Devia, G.K., Ganasri, B.P., Dwarakish, G.S., 2015. A review on hydrological models. Aquatic Procedia 4, 1001-1007.

Dillman, D.A., 2000. Mail and Internet Surveys: The Tailored Design Method. Wiley, New York.

Drew, C.A., Perera, A.H., 2012. Expert knowledge as a basis for landscape ecological predictive models. In: Perera, A.H., Drew, C.A., Johnson, C.J. (Eds.), Expert Knowledge and its Application in Landscape Ecology. Springer, New York.

Faulkner, D., Kjeldsen, T., Packman, J., Stewart, L., 2012. Estimating Flood Peaks and Hydrographs for Small Catchments: Phase 1. Environment Agency, Horizon House, Bristol.

Fiorese, G., Catenacci, M., Verdolini, E., Bosetti, V., 2013. Advanced biofuels: future perspectives from an expert elicitation survey. Eneroy Policy 56 (2013), 293-311.

Gebre, F., Nicholson, O., 2012. Flood estimation in small and urbanised catchments in Ireland. In: Proceedings of the Irish National Hydrology Conference 2012, Tullamore, 13 November 2012, pp. 88-100.

Grabs, W., 2009. Bridging the observational gap. World Water Develop. Rep. 3, 226-236.

Hannaford, J., Marsh, T.J., 2008. An assessment of trends in UK high flow magnitude and frequency using a network of undisturbed catchments. Int. J. Climatol. 28, $1325-1338$.

Hannah, D.M., Demuth, S., van Lanen, H.A.J., Looser, U., Prudhomme, C., Rees, G., Stahl, K., Tallaksen, L.M., 2011. Large-scale river flow archives: importance, status and future needs. Hydrol. Process. 25, 1191-1200.

Hardigan, P.C., Popovici, I., Carvajal, M.J., 2016. Response rate, response time, and economic costs of survey research: a randomized trial of practicing pharmacists. Res. Soc. Admin. Pharm. 12 (1), 141-148.

Kalantari, Z., Lyon, S.W., Folkeson, L., French, H.K., Stolte, J., Jansson, P.E., Sassner, M., 2014. Quantifying the hydrological impact of simulated changes in land use on peak discharge in a small catchment. Sci. Total Environ. 466 (2014), 741-754.

Kannan, N., White, S.M., Worrall, F., Whelan, M.J., 2007. Sensitivity analysis and identification of the best evapotranspiration and runoff options for hydrological modelling in SWAT-2000. J. Hydrol. 332 (3), 456-466.

Kløve, B., Ala-Aho, P., Bertrand, G., Gurdak, J.J., Kupfersberger, H., Kværner, J., Muotka, T., 2014. Climate change impacts on groundwater and dependent ecosystems. J. Hydrol. 518 (2014), 250-266.

Knol, A.B., Slottje, P., van der Sluijs, J.P., Lebret, E., 2010. The use of expert elicitation in environmental health impact assessment: a seven step procedure. Environ. Health 9 (1), 19.

Mishra, A.K., Coulibaly, P., 2009. Developments in hydrometric design: a review. Rev. Geophys. 47 (2).

MacCárthaigh, M., 2002. Parameters of low flow and data on low flows in selected Irish rivers. In: Proceedings of the National Hydrology Seminar, Ireland 2002, pp. 64-71.

Murphy, C., Harrigan, S., Hall, J., Wilby, R.L., 2013. HydroDetect - The Identification and Assessment of Climate Change Indicators for an Irish Reference Network of River Flow Stations. Environmental Protection Agency, Johnstown Castle Estate, Co. Wexford, Ireland.

Nasr, A.E., Hynds, P.D., 2017. Assessment of the Hydrometric Network and Hydrodynamic Behaviour of Small Irish Catchments. EPA Research Report 218.

Naughton, O., Hynds, P.D., 2013. Public awareness, behaviours and attitudes towards domestic wastewater treatment systems in the Republic of Ireland. J. Hydrol. 518 (A), p108-119.

O'Hagan, A., Oakley, J.E., 2004. Probability is perfect, but we can't elicit it perfectly. Reliab. Eng. Syst. Saf. 85 (1), 239-248.

Pyrce, R.S., 2004. Review and analysis of stream gauge networks for the Ontario stream gauge rehabilitation project. In: Watershed Science Centre (Trent University, Peterborough, Ontario), pp. 90.

Rodda, J.C., 1997. On the problems of assessing the world's water resources. In: Geosciences and Water Resources: Environmental Data Modeling. Springer, Berlin, Heidelberg, pp. 13-32.

Spence, C., Saso, P., Rausch, J., 2007. Quantifying the impact of hydrometric network reductions on regional streamflow prediction in northern Canad. Can. Water Resour. J. 32 (1), 1-20.

Truong, Phuong N., Heuvelink, Gerard B.M., 2013. Uncertainty quantification of soil property maps with statistical expert elicitation. Geoderma 202 (2013), 142-152.

Viglione, A., Borga, M., Bloschl, G., 2010. Barriers to the exchange of hydrometeorological data in Europe. J. Hydrol. 394, 63-77.

Walker, B., Abel, N., Anderies, J., Ryan, P., 2009. Resilience, adaptability, and transformability in the Goulburn-Broken Catchment, Australia. Ecol. Soc. 14 (1).

Werstuck, C., Coulibaly, P., 2017. Hydrometric network design using dual entropy multiobjective optimization in the Ottawa River Basin. Hydrol. Res. 48 (6), 1639-1651.

Zheng, H.X., Chiew, F.H., Charles, S., Podger, G., 2018. Future climate and runoff projections across South Asia from CMIP5 global climate models and hydrological modelling. J. Hydrol. Reg. Stud. 18, 92-109. 